\title{
ANATOMICAL STUDY ON INTRA-PAROTID COURSE OF FACIAL NERVE AND ITS TERMINAL BRANCHES
}

Kalai Anbusudar, Balaji Arumugam

1. Assistant Professor. Department of Anatomy, Government Dharmapuri Medical College, Dharmapuri, Tamilnadu, India.

2. Assistant Professor. Department of Community Medicine, A. C. S Medical College, Chennai, Tamilnadu, India.

\section{CORRESPONDING AUTHOR:}

Dr. Kalai. Anbusudar,

Assistant Professor, Department of Anatomy,

Govt Dharmapuri Medical College,

Dharmapuri, Tamilnadu, India.

E-mail: anbujeyanth@gmail.com

ABSTRACT: INTRODUCTION: Face is essential to express emotion, consciously or unconsciously. The face plays a crucial role in determining a person's character with a single glance. Given that the face plays an important part in an individual's life. Surgeries performed on any part of the face, be it a parotid glad removal, facial reconstructive surgery or a cosmetic surgery, have become quite frequent and incredibly popular. The popularity continues to rise with general surgeon, oro-maxillo-facial surgeons, dental surgeons, oto-rhinolaryngologists, and plastic surgeons performing a wide range of operations such as parotidectomy, rhytidectomy, surgeries in the submandibular region and mandibular ramus fractures. MATERIALS: Study on the intraparotid course of facial nerve had been conducted in 50 specimens of face. Of 17 male and 8 female cadavers, in the Institute of Anatomy, Madras Medical College, Chennai. RESULTS: There was only one trunk in all the specimens (100\%). The facial nerve in all the specimens had two major division, upper temporofacial and lower cervicofacial division. In $92 \%$ of specimens the buccal branch arose from these two divisions. In $8 \%$ of specimen the buccal branch had an additional contribution by a central branch which came directly from the trunk. In $64 \%$ of specimens the buccal branch was found to be inferior to parotid duct. The buccal branch was below the line joining the tragus and ala of nose. The marginal mandibular (MMB) branch was one to four in number. The marginal mandibular branch was usually below the inferior border of mandible. The mean distance between the marginal mandibular branch and inferior border of mandible was $10.76 \mathrm{~mm}$. The marginal mandibular branch crossed the facial artery mostly superficially. The MMB had no anastomosis with other branches, but minimal percentage of anastomosis with the buccal and cervical branches. The temporal branch was within the line joining the tragus and lateral palpebral commissure. The extra parotid ramification (branching of facial nerve) was approximately 55\% of LPL. CONCLUSION: Knowledge of the results obtained in this study may help to decrease the iatrogenic injury to the facial nerve during removal of Parotid gland, and face lifting surgeries.

KEY WORDS: facial nerve, parotid duct, buccal branch, marginal mandibular branch, retromandibular vein

INTRODUCTION: The face plays a crucial role in determining a person's character with a single glance. Given that the face plays an important part in an individual's life. Surgeries performed on any part of the face, be it a parotidectomy, facial reconstructive surgery or a cosmetic 
surgery, have become quite frequent and incredibly popular. The popularity continues to rise with general surgeons, Oro-maxillo-facial surgeons, dental surgeons, Oto-rhinolaryngologists, and plastic surgeons performing a wide range of operations such as: Parotidectomy in Parotid Gland tumours, face lifting surgeries in Rhytidectomy, Surgeries in the submandibular region and Mandibular ramus fractures. In case of these types of surgeries, there is more risk of injury to the Facial Nerve when removing the gland tissue since the Facial Nerve is coursing in a complex pattern within the Parotid Gland. The risk of injury to the Buccal branch is more, since it has a close relationship to the parotid duct. The major motor supply around the nose and the mouth is by the Buccal branch of Facial Nerve. In case of injury to this nerve the unbalanced facial muscles and the inability to close the eyelids or to chew the food, may lead the patient to tremendous psychic trauma, like inferiority complex.

The Temporal and Zygomatic branches may get injured in cases of trauma to the zygoma that leads to inactivation of orbicularis oculi and the patient is unable to close the eyelid. Given that the face plays an important part in determining attractiveness, it makes sense that the cosmetic facial surgery is wide spread. In reconstructive and aesthetic surgery, especially in the face, it is very important to consider the surgical anatomy of the Facial Nerve.

For this reason, it is imperative that surgeons who are responsible for managing such surgeries should have a thorough knowledge of anatomy of Facial Nerve. Even though there are lot of literatures documenting the Facial Nerve anatomy, accidental injury to the trunk, divisions and branches of Facial Nerve during the above mentioned surgeries is continuing and causing disfigurement to the patient and psychic depression. Thus an interest in the anatomy of the Facial Nerve in the face especially in the intra parotid course, made me to conduct this study in a detailed manner.

\section{AIMS AND OBJECTIVES}

1. To study the course, number of trunks, branches, location of the branches, branching pattern, relations with branches, anastomosis of the branches

2. To assess the clinical significance of the branches in relation to surgeries

\section{MATERIALS AND METHODS}

\section{METHOD OF STUDY - DISSECTION METHOD}

- Conventional dissection method

SPECIMEN COLLECTION: Twenty five adult embalmed human cadavers were selected from the cadavers allotted for the first year MBBS students and first year BDS students at the Institute of Anatomy, Madras Medical College, Chennai during the period of 2009-2012.

CONVENTIONAL DISSECTION METHOD: The adult cadaver was placed in supine position and placed a block under the back of head to raise it to a convenient angle. A median incision made into the skin of the scalp from the root of the nose to the external occipital protuberance, and a coronal incision from the middle of the first cut to the root of each auricle. This was continued behind the auricle to the mastoid process and in front of it to the root of the zygomatic arch. The upper part of the orbicularis occuli was exposed and the frontal belly of occipitofrontalis was followed from below upwards. The anterior part of epicranial aponeurosis and its downward extension into the temple were exposed. Two or more temporal branches of the Facial Nerve 
were found which crossed the zygomatic arch $2 \mathrm{~cm}$ or more in front of the auricle. Most of the facial muscles were detached. The facial artery and vein were traced at the antero inferior angle of the masseter and traced forwards. The fascia covering of the Parotid Gland was cut immediately in front of the auricle from the zygomatic arch to the angle of the mandible.

The fascia was dissected carefully forwards to the margins of the gland, and looked for the nerves, vessels and the duct of the gland which emerge at the borders. The duct appeared at the anterior border about a finger's breadth below the zygomatic arch. Above the duct, a small detached part of the Parotid Gland, the accessory parotid, the transverse facial artery and vein and the Zygomatic branches of the Facial Nerve were traced. The other branches of Facial Nerve were traced which emerged out from the anterior border of Parotid Gland were traced them forwards. The upper Zygomatic branches of the Facial Nerve were followed first. They passed deep to the Zygomatic muscles. The Buccal branch of the Facial Nerve was found at the anterior border of the Parotid Gland. It was traced forwards through the fat of the cheek to the buccinator muscle. The Marginal Mandibular branch of Facial Nerve was traced forwards from the lower border of the Parotid Gland to the depressor anguli oris. At the lower border of the gland, the anterior and posterior branches of retromandibular vein, the Cervical branch of Facial Nerve were identified. One of the branches of the Facial Nerve was followed back through the gland to the trunk of the Facial Nerve. The retromandibular vein and external carotid artery were exposed by removing more of the gland. During this dissection the Parotid Gland was removed piece meal.

\section{To observe the location of Temporal branch of Facial Nerve}

- A pin was put on the tragus and marked as a

- Another pin was put on the lateral palpebral angle (the outer corner of the eye fissure where the eyelids meet) and marked as $\mathbf{b}$

- These two points were joined by a thread and marked as line I.

- Third pin was put at the inferior attachment of ear lobe to the skull and marked as c

- Fourth pin was at lateral edge of coronal suture and marked as d

- The pins $\mathbf{c}$ and $\mathbf{d}$ were joined by a thread and marked as line II.

- It was observed whether the location of Temporal branches of Facial Nerve falls within the lines I and II or not.

2. Location of Buccal Branch of Facial Nerve

- A pin was put on the tragus (e) and another pin over the ala of nose (f)

- These two pins were joined by a thread and marked as line III. A pin was put on the tragus (g) and another pin over the middle of upper lip (h)

- These two pins were joined and marked as line IV.

- Observed for the Buccal rami whether located below the line III or below the line IV.

3. Distance between Marginal Mandibular branch and inferior border of mandible

- The lower most part of MMB was noted. The vertical distance between the lower most point of Marginal Mandibular branch and inferior border of mandible was measured using a flexible measuring tape. The mean, standard deviation (SO) and range were assessed. 


\section{Locating the extra parotid ramification of Facial Nerve (Locating the Facial Nerve branching)}

The lateral palpebral line (line $\mathbf{V}$ ) a vertical line passing through the lateral palpebral angle (the outer corner of the eye fissure where the eyelids meet), parallel to the average sagittal plane of the face was introduced as a reference line for surgical landmark of Facial Nerve ramification.

The reference points were marked by putting the pins into the Lateral palpebral angle (i) and Otobasion superious (OBS) (j) (The highest point of attachment of the external ear to the head). The skin was carefully removed; the boundary of the Parotid Gland was identified. Another pin was put over the anterior most point of anterior border of Parotid Gland and marked referred as A(k).

The vertical line passing through the OBS marked as line VI and the vertical line passing through A marked as line VII.

The distance from LPL to the OBS (LPL-OBS) and the anterior most point of anterior border of Parotid Gland (A) (LPL-A) were determined in order to locate the area of Facial Nerve branching in relation to the LPL.

The mean, standard deviation (SD) and range of each measurement were assessed.

RESULTS: In this study all the 50 specimens (100\%) had only one trunk(Fig1), two divisions, namely the temporofacial and the cervicofacial and five branches, namely the temporal, zygomatic, buccal, marginal mandibular and cervical. The temporal and the zygomatic branch were branched out from upper temporofacial division in all specimens. The marginal mandibular and the cervical branches were branched out from the lower cervicofacial division. In 46 specimens (92\%) the buccal branch was formed by both the divisions (Fig3). But in 4 specimens (8\%) the buccal branch had contributions from both the divisions and an additional branch directly from main trunk(Fig2). In 32 specimens (64\%) the buccal branch was inferior to the parotid duct and in 12 specimens (24\%) it was superior to the parotid duct. But in 6 specimens $(12 \%)$ it was not united but passed as upper buccal and lower buccal(Table1). In these 6 specimens the upper buccal was superior to the parotid duct and the lower buccal was inferior to the parotid duct (Fig4). The buccal branch was located below the line joining the tragus and ala of nose in all 50 specimens.

The number of marginal mandibular branch (MMB) was variable. One in 19 of specimens (38\%), 2 in 25 of specimens (50\%), 3 in 3 specimens (6\%) and 4 in 3 specimens (6\%)(Table2). The MMB ran below the inferior border of mandible in 46 specimens (92\%)(Fig5) and above the inferior border of mandible in 4 specimens(8\%). The distance between the MMB and the inferior border of mandible was ranged from $7 \mathrm{~mm}$ and $14 \mathrm{~mm}$ and the mean was $10.76 \mathrm{~mm}$ (Fig6). In 42 specimens (84\%) the MMB ran anterior to the facial artery (Fig7) and in 8 specimens (16\%) it ran posterior to the facial artery (Fg8)(Table3). The MMB had no anastomosis with other branches of facial nerve in 36 specimens (72\%), had anastomosis with buccal branch in 12 specimens (24\%) (Fig9) and with cervical branch in 2 specimens (4\%) (Fig10)(Table4).

In all 50 specimens the temporal branch was located between the two lines, one oblique line extending from tragus to the lateral canthus of eye, and another line extending from the lower attachment of ear lobe to the lateral end of coronal suture (Fig11). The distance between the LPL and OBS, and the distance between the anterior most point of anterior border of parotid gland (A) were measured in all 50 specimens (Fig12). The distance between the LPL and 
anterior most point of anterior border of parotid gland (A) was ranged from $34 \mathrm{~mm}$ to $48 \mathrm{~mm}$ with a mean of $39.64 \mathrm{~mm}$. The distance between the LPL and OBS was ranged from $64 \mathrm{~mm}$ to $88 \mathrm{~mm}$ with a mean of $73.94 \mathrm{~mm}$. The proportion of LPL -anterior most point of anterior border of parotid gland (A) to LPL-OBS was ranged from $50 \%$ to $56 \%$ with a mean of $53.7 \%$.

In 48 specimens (96\%) the trunk and divisions of facial nerve were passed superficial to the retromandibular vein. But in 2 specimens (4\%) the retromandibular vein was passed within a loop which was formed by the temporofacial division (Fig13).

DISCUSSION: Many studies are there on extra cranial course of facial nerve and on individual terminal branches of facial nerve. Chummy ${ }^{6}$ (1999) and Susan Standring (2008) stated that the trunk of facial nerve entered the parotid gland and divided into two major divisions ${ }^{6}$. Kilik et al (2010) found double facial nerve trunk. Katzand Catalano (1987) found two main trunks, major and minor trunk in 3\% of cases. Young Soon Kim M.D. (2002) found two major divisions in 23 faces $(15 \%)$, three trunks upper, lower and middle buccal trunk. The present study correlates with this study with slight difference in the percentage of occurrence. Henry Hollinshed ${ }^{6}(1962)$ and R.M.Kirk(2000) stated that the buccal branch usually arise either from lower part or from both upper and lower part of the nerve which coincides with our study. But Farooq Ahmed et al(2005) found the buccal branch arose from the upper division in 42\%, from lower division in $52.6 \%$ and from both division in 5.2\%. In Pogrel ${ }^{13}$ (1996) study the buccal branch was inferior to the parotid duct in $75 \%$ of cases whereas in $25 \%$ of cases the nerve crossed the duct usually from superior to inferior and this study correlates with the present study with slight difference in the percentage of occurrence. Samerendra Mitra ${ }^{14}$ (1982) and Josef E.Fischer (2008) stated in their study that the upper buccal passed superior to the parotid duct and the lower buccal passed inferior to the parotid duct which was similar to $12 \%$ of specimens in our study. Ekaritt Weerapant et $\mathrm{al}^{9}$ (2010) found the buccal branch lie below the line that joined the tragus and the ala of nose and the same found in our study also (Table5). Kim DT et al (2009) stated that the Marginal Mandibular branch was one in 28\%, two in 52\%, three in $18 \%$ and four in $2 \%$ of cases. Al- Hyani $\mathrm{A}^{1}(2007)$ and Yalcin Kirichi et $\mathrm{al}^{16}$ (2011) stated in their study that the no: of MMB was 1 in $32 \%$ and $38.7 \%$ and 2 in $40 \%$ and 61.35 respectively. This study nearly correlates with the present study (Table7). Baker \& $\operatorname{Conky}^{3}$ (1976) , John J Coleman ${ }^{7}(2000)$ and Sir Alfred Cuschieri et al (2002) stated that the MMB ran 1 to $2 \mathrm{~cm}$ below the inferior border of Mandible which coincides with the present study(Table6). Dingman and Grabb (1962) told that the MMB ran above the inferior border of mandible in $81 \%$ and ran below the inferior border of mandible in $19 \%$ of cases and the distance between the inferior border of mandible and the MMB was about $1 \mathrm{~cm}$ or less than $1 \mathrm{~cm}$. Charles W Cummings ${ }^{8}$ (2005), Kevin G et al(2005) and Stephen J Mathes (2006) found that the MMB was usually anterior (superficial) to the facial artery which partially correlates with the present study. Wang TM et al (1991) stated that in $83 \%$ the MMB was superficial to the facial artery and in only $2 \%$ deep to the facial artery. The remaining 15\%ran deep and superficial to the artery (Table8). The MMB had no anastomosis with the other branches of facial nerve in $60 \%$ of cases and had anastomosis with buccal branch in $40 \%$ of cases in KimDT et al(2009). But in Yalcin Kirici et al (2011) study MMB had interconnection with buccal branch \& cervical branch in $25.8 \%$ and $12.9 \%$ of cases respectively which correlate with the present study with some differences (Table9). Gosain AK(1995) and Rodrigues D.C. et al (2009) found the temporal branch lie within an oblique line joining the lower part of the auricle and the lateral aspect of eyebrow. Ekaritt Weerapant et al (2010) stated that the proportion of LPL-AP to LPL-OBS was about $54.5 \%$ which correlates with our 
present study(Table10). Romanes G.J (1972) , Tardy M.E. and Kasten bauer E.R (1995) stated that the facial nerve and its divisions were usually superficial to the retromandibular vein. Rajesh B. Astik et al (2011) found the main trunk of the facial nerve and its divisions were forked between the maxillary and superficial temporal veins. The present study correlates with above said study.

CONCLUSION: The intraparotid course of facial nerve was composed of variations in branching pattern and relation between parotid duct and retromandibular vein. This will provide a guideline to the general surgeon while performing Parotidectomies. The location of temporal branch, buccal branch and extra parotid ramification of all branches were also explained which will help the plastic surgeons while performing surgeries in face. The Marginal Mandibular nerve and its close relationship to the facial artery and the inferior border of mandible and its anastomosis were documented in detail. It will help the surgeons to handle the submandibular region in case of submandibular excision.

\section{REFERANCES:}

1. Al-Hayani A ,Anatomical localization of Marginal Mandibular branch of facial nerve; Folio morphol (warsz), 2007,vol 66(4);page no: 307-13.

2. Arvinder Pal singh Batra, Anupama Mahajan and Kerunesh Gupta, Marginal Mandibular branch of the facial nerve; An anatomical study; Indian J Plast Surg.,/2010 Jan - Jun;vol 43(1); page no:60-64.

3. Baker DC, Conky J, Avoiding facial nerve injuries in rhytidectomy. Anatomical variations and pitfalls. Plast. Recont. Surg., 1979; vol 64 page no:(781-95)

4. Callandar C.L. ,Surgical anatomy, $2^{\text {nd }}$ edition,1979, 121-122.

5. Cenk Kilic, Yalcin Kirici and Murat Kocaoglu, Double facial nerve trunk emerged from the stylomastoid foramen and petrotympanic fissure; A case report; J. Korean Med Sci ,2010;vol 25; page no:1228-1230.

6. Chummy S. Sinnatamby ,Last's anatomy Regional and applied;, 11 thedition. 1999, page no: 344,345

7. Coleman John. J., Plastic surgery Indications, Operations and Outcomes, 2000 Vol. 3, page no:1358-1385.

8. Cummings W. Charles, Otolaryngology, Head and Neck Surgery; $4^{\text {th }}$ edition; (2005) ,page no:1339-1347, 1367

9. Ekaritt Weerapant, Tnaom Bunaprasert ,Anatomy of Facial nerve branching patterns, the Marginal Mandibular branch and its extra parotid ramification in relation to the lateral palpebral line; ,Asian biomedicine 2010, vol. 4, No.4 August, page no: 603-608.

10. Henry Hollinshead. W. ,2nd edition, Vol. 1, Anatomy for Surgeons; 1962, page no:352 to 358

11. Henry Hollinshead. W. , Textbook of Anatomy; 1962, page no:875 to 879.

12. Kopuz C, Ilgi S, Yavuz S, Onderoglus, Morphology of the retro mandibular vein in relation to the facial nerve in the parotid gland; Acta Anat. (basel); 1995; vol 152(1), page no:668.

13. Pogrel M.A. Schnidt B, Ammar A, The relationship of the buccal branch of the facial nerve to the parotid duct; J Oral maxilla facial Surg. 1996 vol Jan; 54(1); page no:71-3.

14. Samarendra Mitra,Anatomy; (1982),page no:5. 20, 5.21.

15. Susan Standring, , Gray's Anatomy, The Anatomical basis of clinical practice; $40^{\text {th }}$ edition, (2008), page no 494,495. 
16. Yalcin Kirichi, Cenk Kilic, Mustafa Kazkayasi, Topographic anatomy of the peripheral branches of the facial nerve; Journ Journal of Experimental and Integrative medicine, 2011;vol 1(3);page no: 201-204.

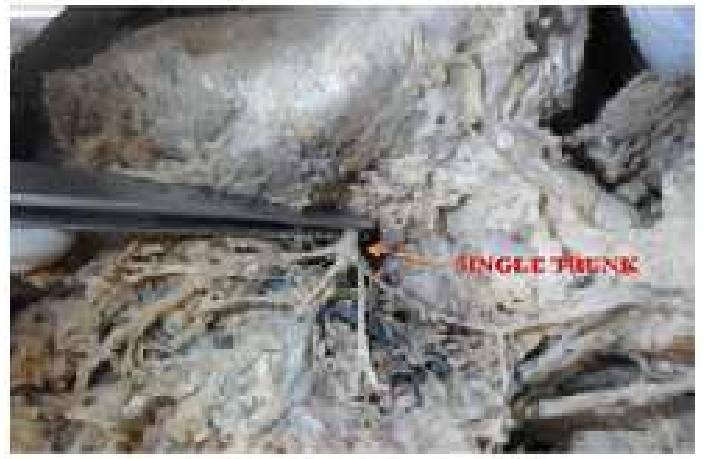

fig 1: no of trunk of facial nerve

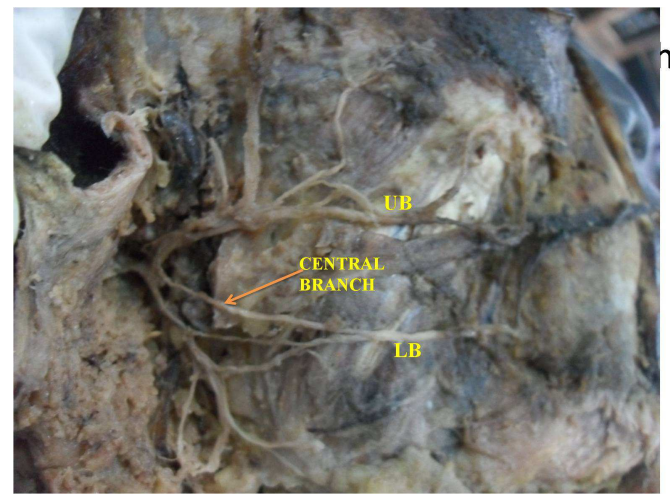

fig 3: origin of buccal branch from both divisions

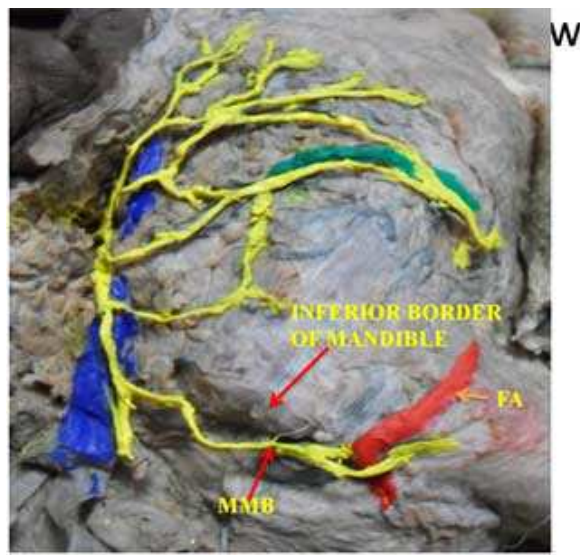

fig 5: mmb below the inferior border of mandible

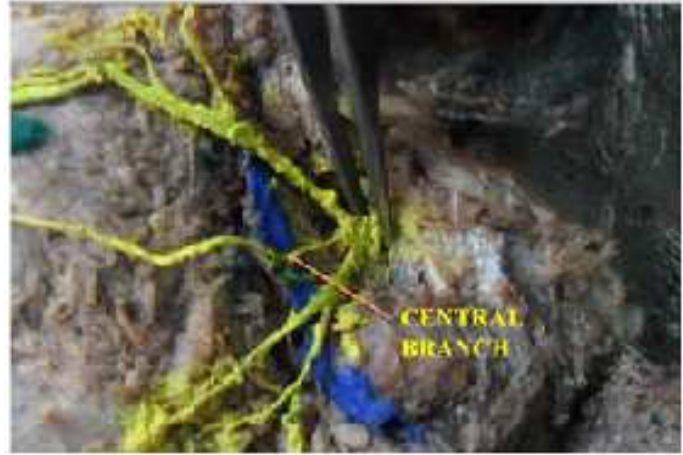

fig 2:origin of buccal branch-additional contribution by addition branch

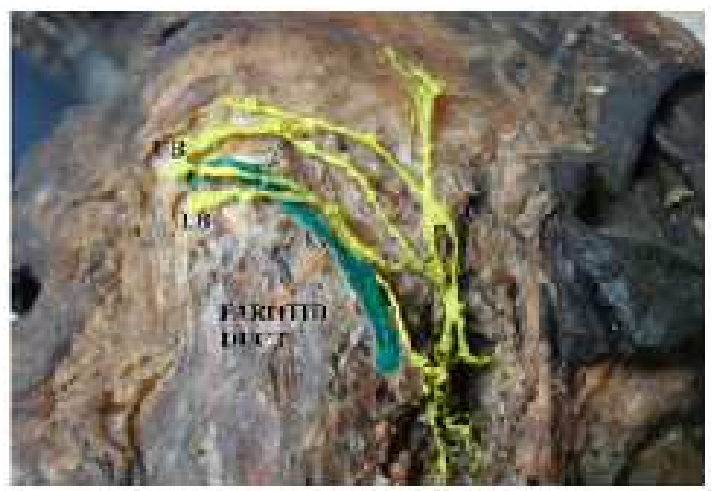

fig 4: relation between buccal branch and parotid duct-one superior and one inferior

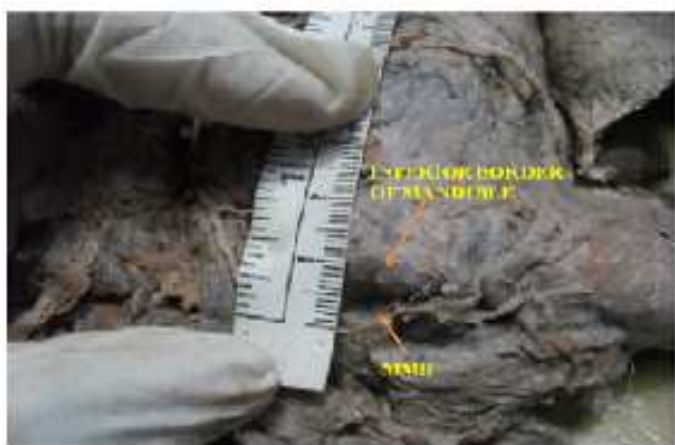

fig 6: distance between mmb and inferior border of mandible 


\section{ORIGINAL ARTICLE}
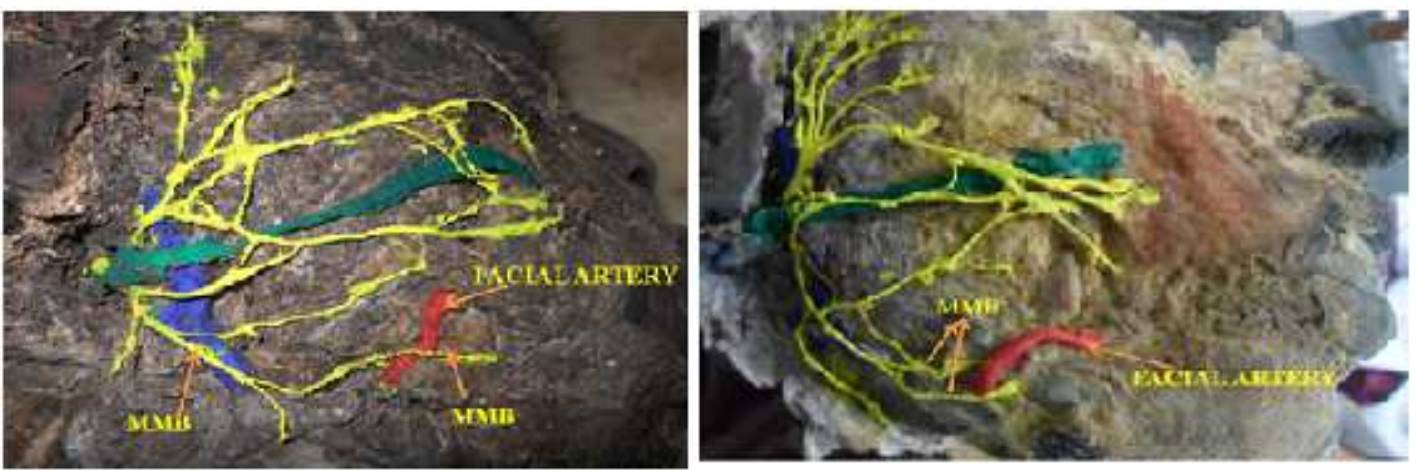

fig 7: $\mathrm{mmb}$ anterior to facial artery

fig 8: mmb-one anterior \&one posterior to artery

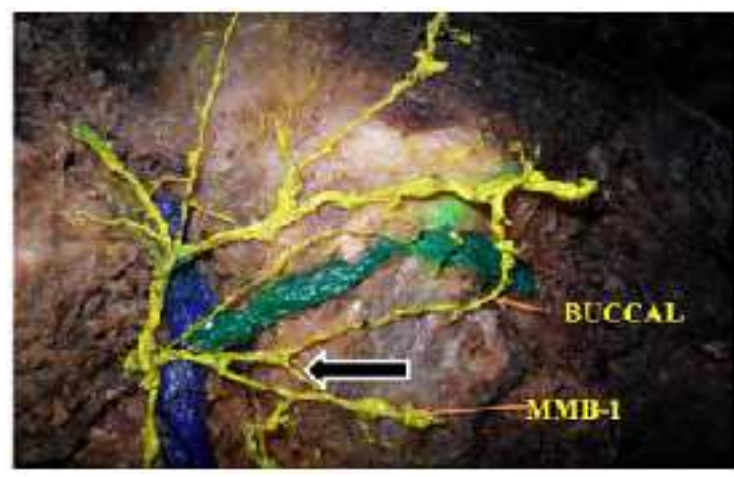

Anastomosis-cervical

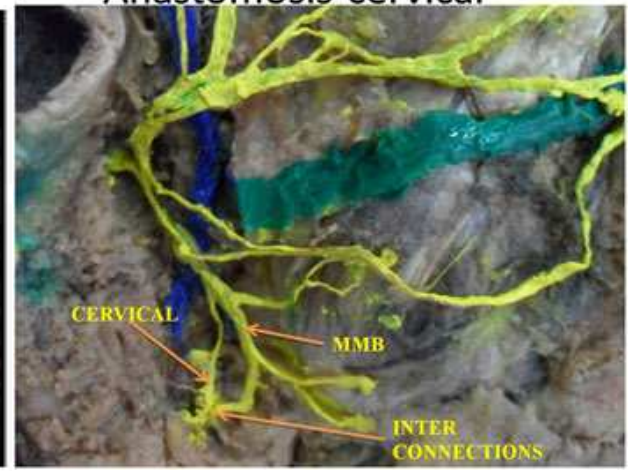

fig 9: anastomosis between $\mathrm{mmb}$ and buccal branch

fig 10: anastomosis between $\mathrm{mmb}$ and cervical branch

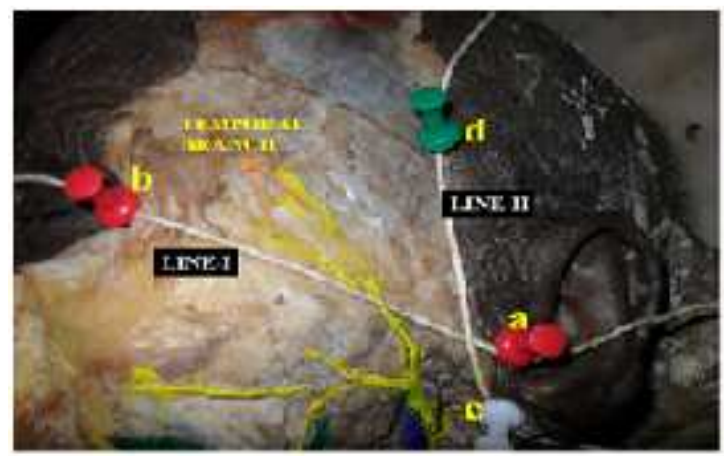

fig 11: locatoin of temporal branch

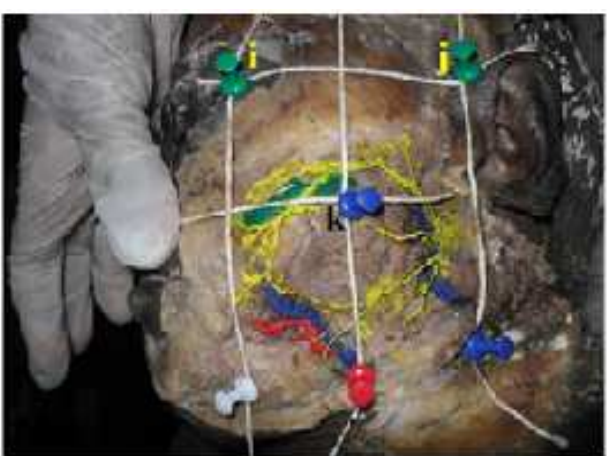

fig 12: distance between lpl-obs 


\section{ORIGINAL ARTICLE}

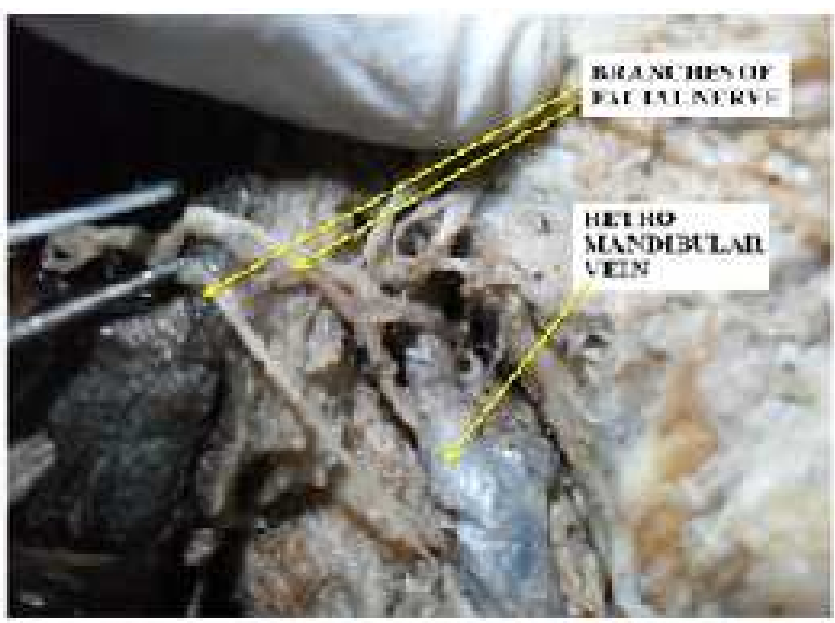

fig 13: retromandibular vein forked between the divisions of facial nerve

\section{Buccal Branch in relation to parotid duct}

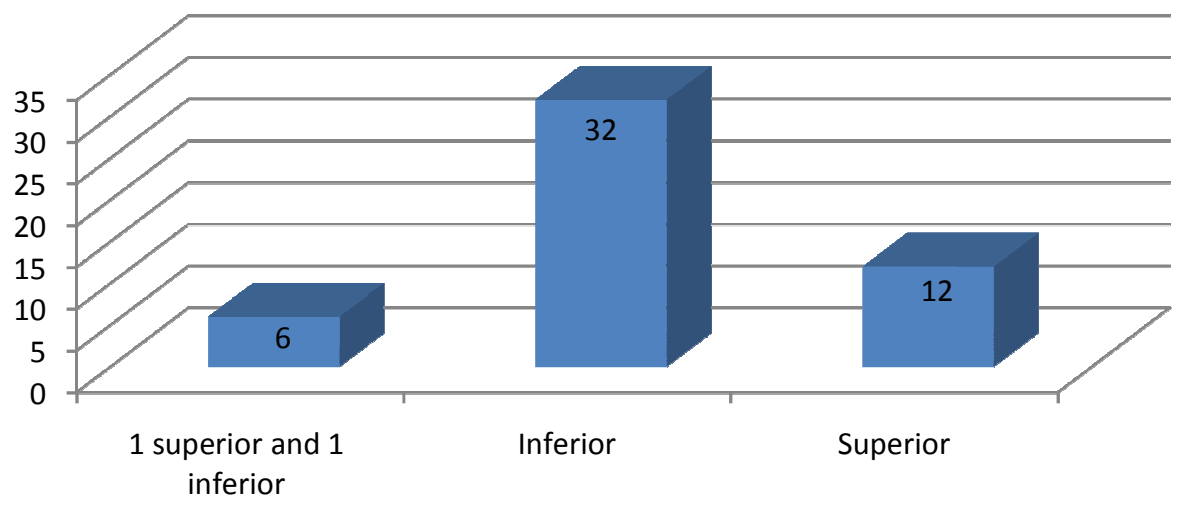

Table 1: relation between buccal branch and parotid duct

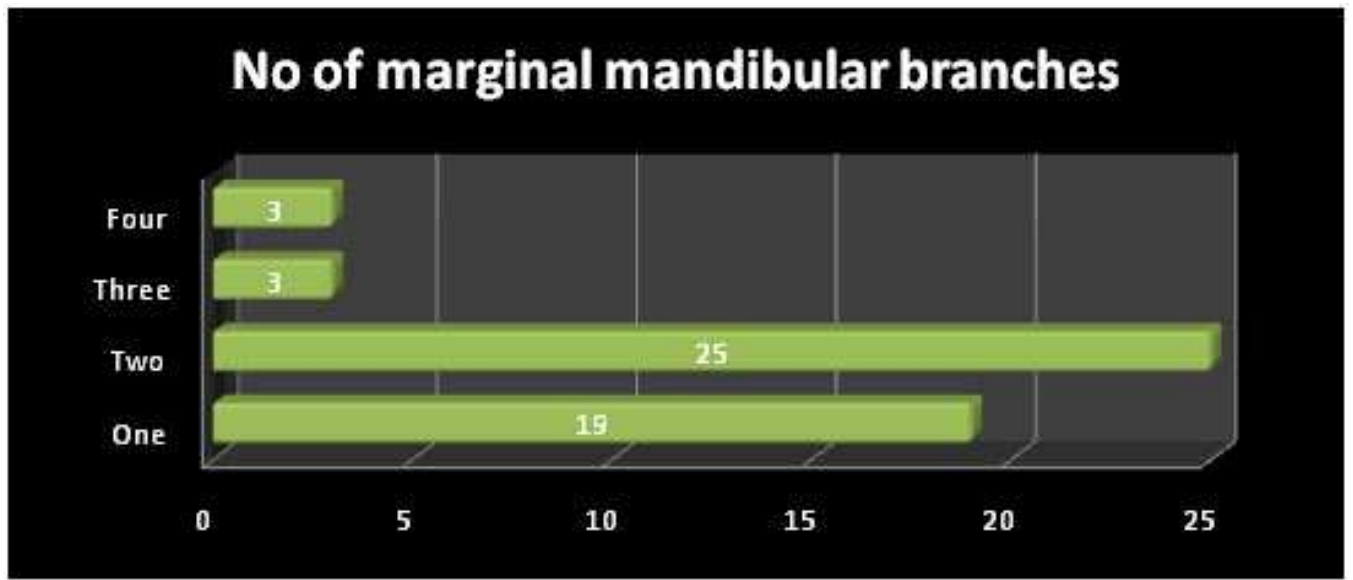

Table 2: no of marginal mandibular branch 


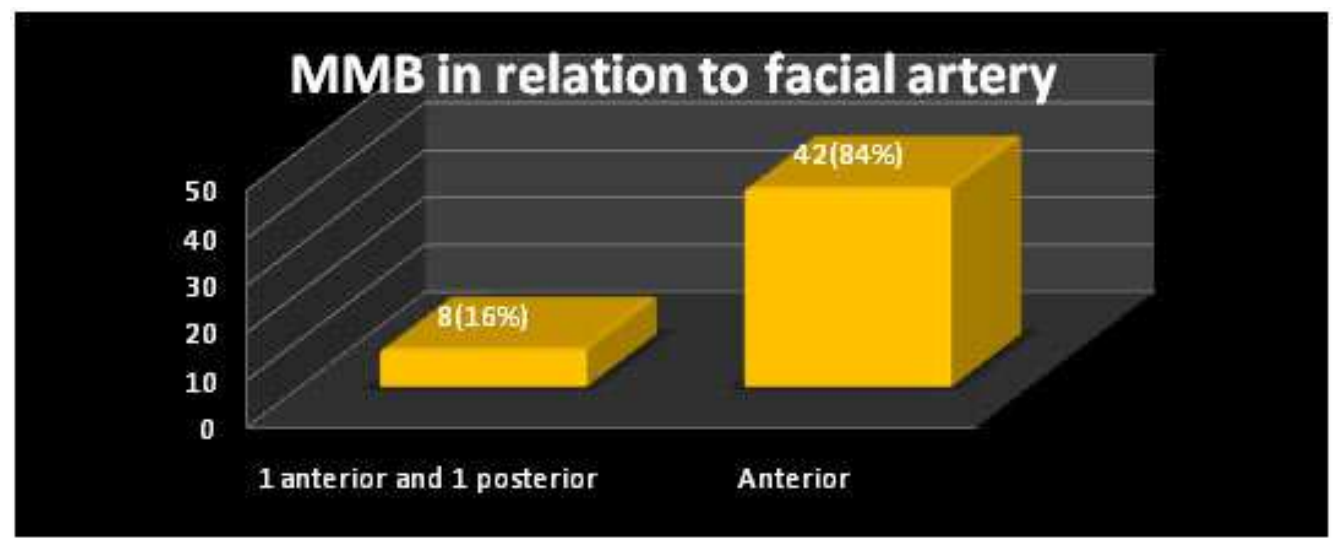

Table 3: relation between facial arteryand $\mathrm{mmb}$

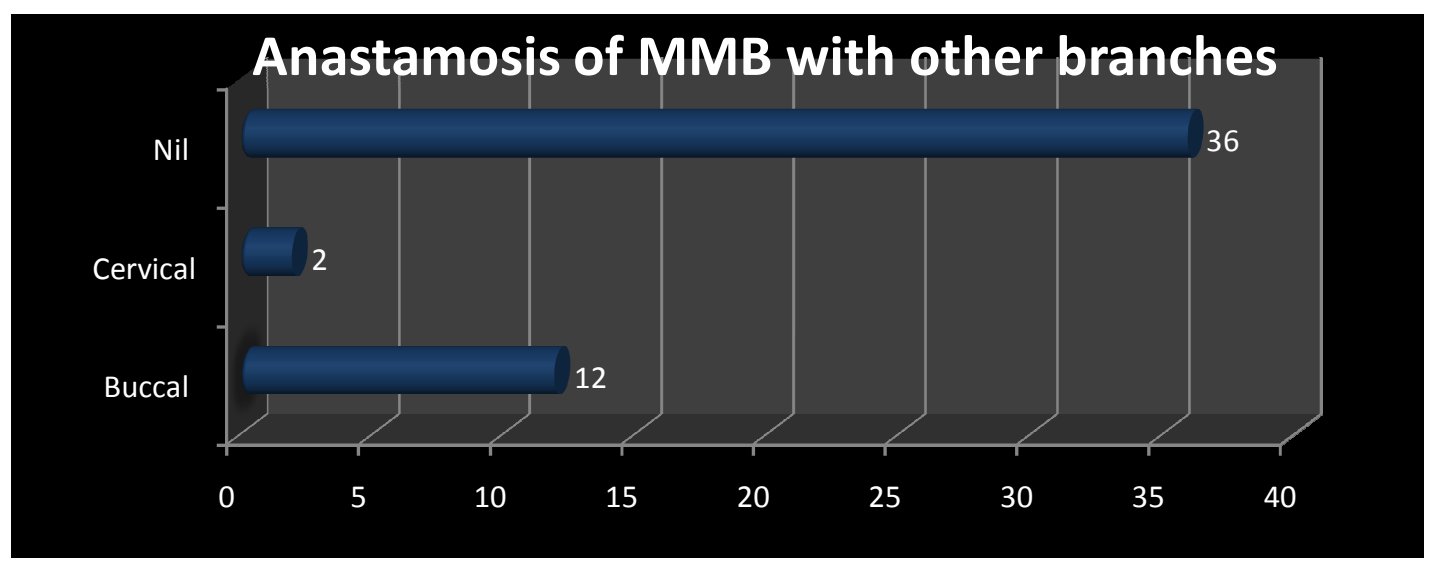

Table 4: anastomosis of mmb with other branches

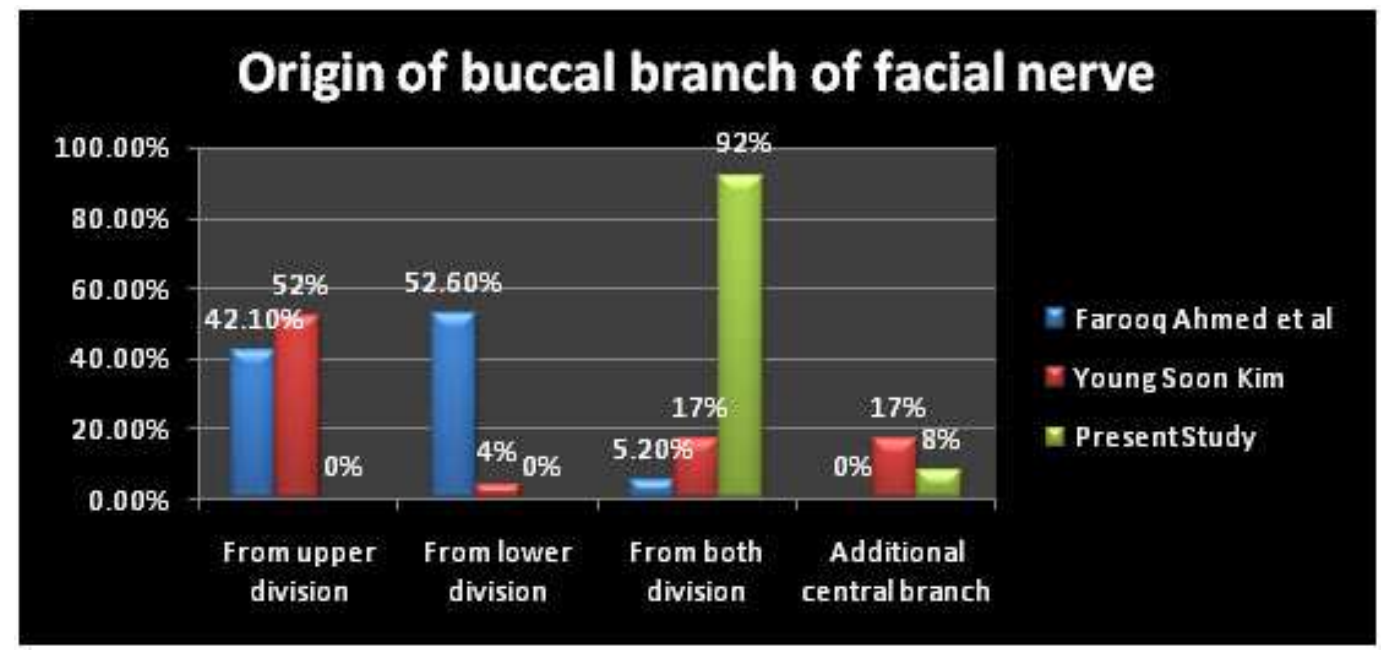

Table 5: origin of buccal branch of facial nerve 


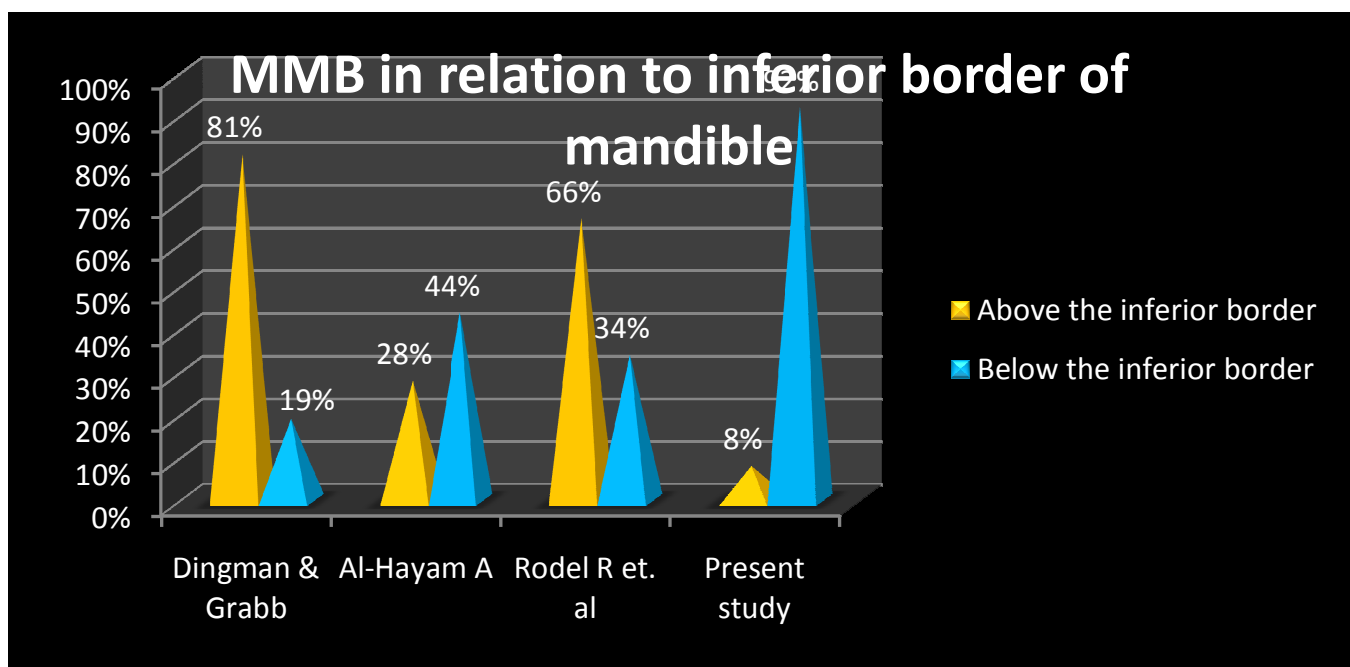

Table 6: relation between $\mathbf{m m b}$ and inferior border of mandible

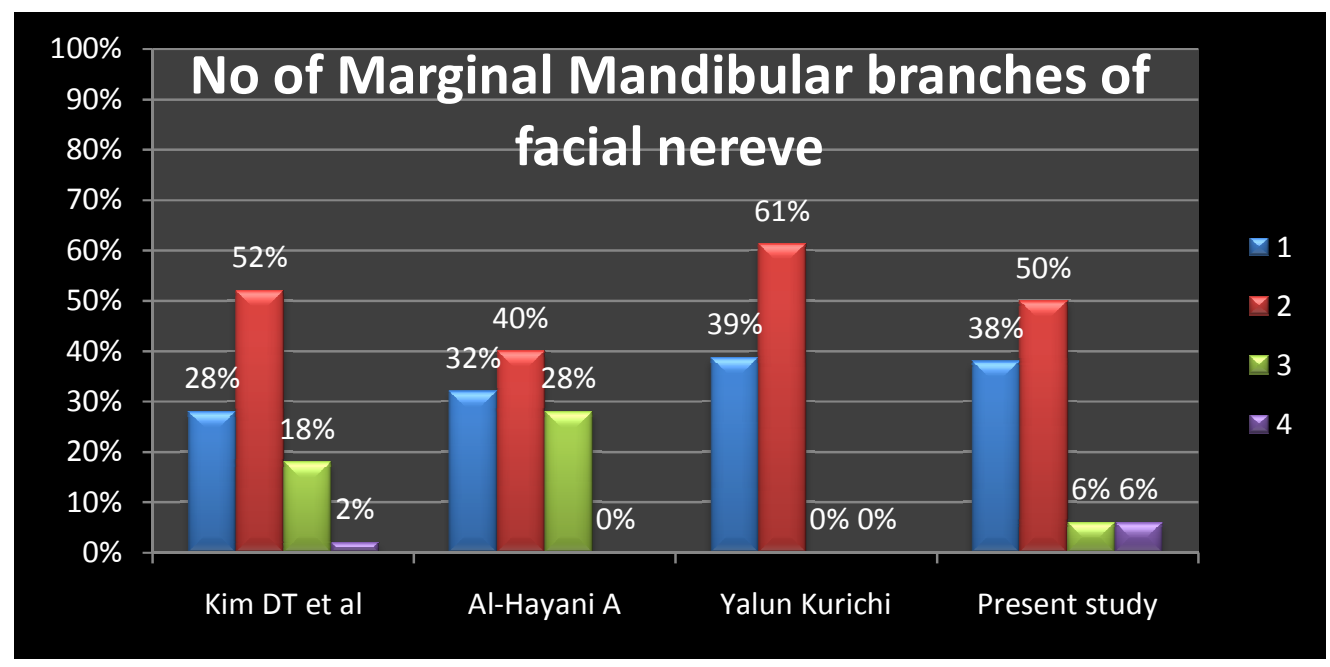

Table 7: no of mmb of facial nerve

\section{MMB in relation to facial artery}

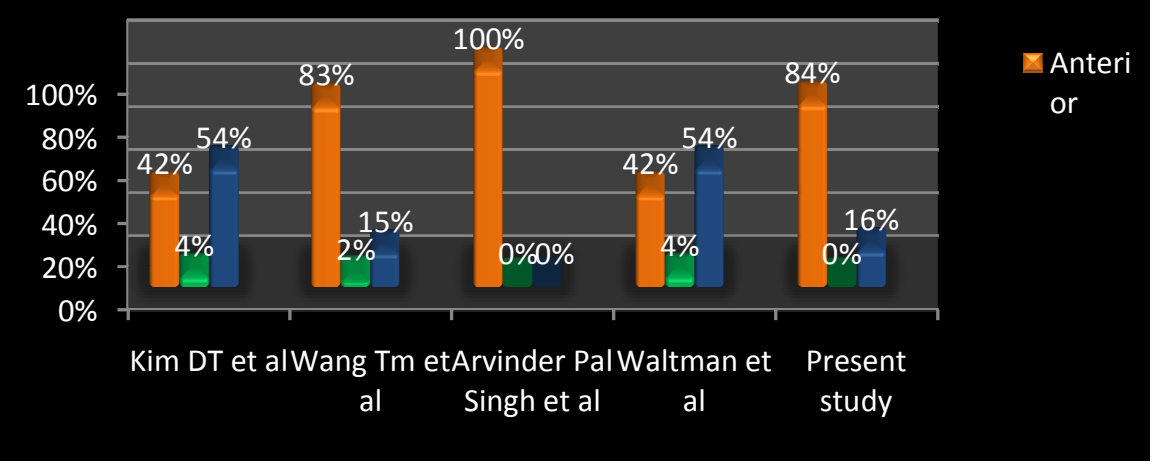

Table 8: $\mathbf{m m b}$ in relation to facial artery 


\section{Anastamosis of MMB with other branches of facial nerve}

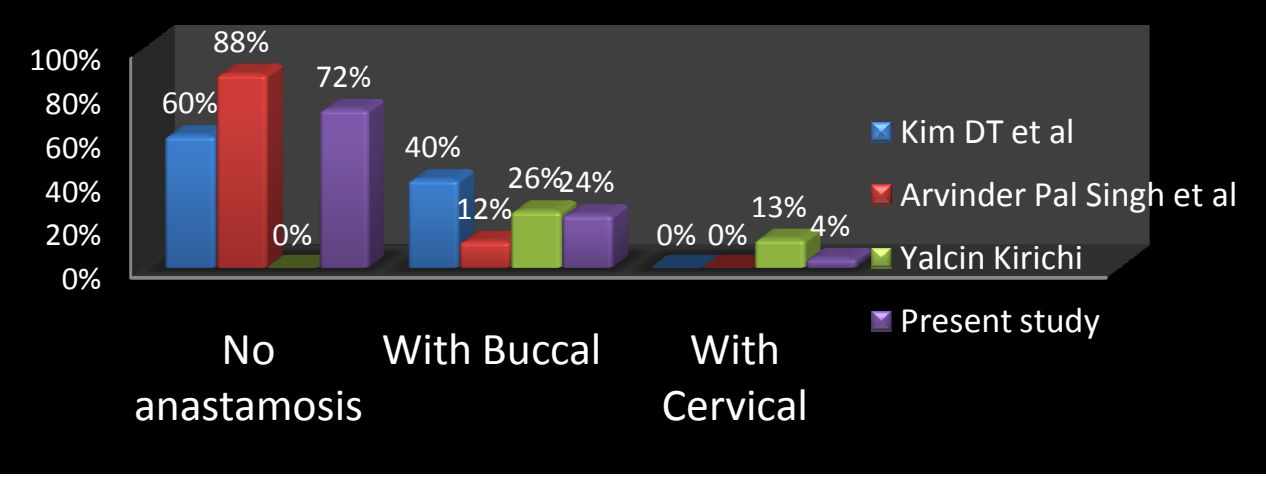

Table 9: anastomosis of mmb with other branches of facial nerve

\section{Location of facial nerve branching in relation to lateral palpebral line - proportion of LPL -P to LAP-OBS}

$53.70 \% \quad 54.50 \%$
Ekaritt Weerapant et al

- Present Study

Table 10: location of facial nerve branches in relation to lpl-a to lpl-obs 